\title{
La coloquialidad en la adaptación cinematográfica del texto teatral: una propuesta de estudio interdisciplinario con el ejemplo de Bajarse al moro
}

\section{Colloquiality in the cinematographic adaptation of the theatrical text: a proposal of interdisciplinary study with the example of Bajarse al moro}

\author{
JuAN GARCÍA-CARDONA \\ Universidad de Wyoming \\ jgarciac@uwyo.edu \\ ORCID ID: 0000-0002-4382- \\ 9818
}

Resumen: Las adaptaciones de una obra literaria al cine son frecuentes. La más directa acaso sea de obra teatral a película, pero incluso en ese caso son necesarios múltiples cambios. Entre ellos se ha destacado por parte de la crítica la necesidad de adaptar el lenguaje de los personajes, sobre todo mediante la "naturalización" de dicho lenguaje por medio de la espontaneidad, la verosimilitud o la simplificación. Para todas estas características se hace fundamental el uso de un registro coloquial. En este estudio, tomando como ejemplo Bajarse al moro de J. L. Alonso de Santos, proponemos un método objetivo y cuantitativo para la comparación de la coloquialidad en la versión teatral y la fílmica de esta obra. Para ello seleccionamos seis escenas teatrales y sus correspondientes versiones fílmicas conforme a diecisiete rasgos sintácticos y léxicos relacionados con la coloquialidad.

Palabras clave: adaptación cinematográfica, teatro, coloquialidad, medidas léxicas, medidas sintácticas, lenguaje vulgar, Alonso de Santos, Bajarse al moro.

\author{
IRENE CHECA-GARCÍA \\ Universidad de Wyoming \\ irene.checa@uwyo.edu \\ ORCID ID: 0000-0002-9022- \\ 6817
}

\begin{abstract}
Literary works adaptations to cinema are frequent. The most direct is perhaps from theatrical play to film, but even in that case, multiple changes are necessary. Among them, the need to adapt the language of the characters, especially through the "naturalization" of said language, has been highlighted by critics, be that by means of spontaneity, credibility, or simplification. For all these characteristics, the use of a colloquial register is essential. In this study, taking as an example Bajarse al Moro by J. L. Alonso de Santos, we propose an objective and quantitative method for comparing colloquiality in the theatrical and the film version. In order to do so, we selected six theatrical scenes and their corresponding film scenes according to seventeen syntactic and lexical features related to colloquiality.
\end{abstract}

Keywords: film adaptation, theater, colloquiality, lexical measures, syntactic measures, vernacular, Alonso de Santos, Bajarse al moro. 


\section{Juan García-Cardona e Irene Checa-García}

\section{INTRODUCCIÓN}

Son numerosos los estudios que han tratado la adaptación al cine de obras literarias centrándose en el desarrollo y proceso que los guionistas han seguido. Una cuestión fundamental que debe tenerse en cuenta a la hora de llevar a cabo una adaptación es el lenguaje utilizado tanto en el texto literario como en el cinematográfico. Guionistas y teóricos han abogado por un proceso de coloquialización en estos textos adaptados, en la búsqueda de un «diálogo natural, desafectado y de apariencia espontánea» (McKee, 2016: 144). Ahora bien, este proceso por el que un texto se hace más coloquial requiere de un estudio detallado y de una delimitación precisa de características de la coloquialidad, para lo que acudiremos al campo de la lingüística.

Hemos escogido, como objeto de análisis, la obra Bajarse al moro de José Luis Alonso de Santos, reconocida como una de las obras teatrales que más emplea el estilo coloquial en sus diálogos. Los rasgos lingüísticos de esta obra han sido estudiados anteriormente de forma cualitativa (Hernando Cuadrado, 2001; Tamayo y Popeanga, 2019), si bien han hecho hincapié principalmente en lo fonético y morfológico, tratando de forma muy breve lo léxico y, en especial, lo sintáctico, de ahí que afirmen estos últimos en su edición para Cátedra que «es un terreno poco explorado, tal vez por su dificultad sistematizadora» (Tamayo y Popeanga, 2019: 73).

Además, la coloquialidad es un rasgo central en los diálogos de Bajarse al moro debido a su conexión con el mundo semi-marginal en el que se mueven los personajes, formando así parte fundamental no solo de su propia caracterización sino de la del entorno. Efectivamente, señala Briz (2011) que existe un cierto estigma de la coloquialidad por asociarse, erróneamente, a un nivel sociocultural medio-bajo. Independientemente de que se trate de una asociación falsa, el hecho es que existe, y es por tanto un factor susceptible de influir sobre la interpretación de la audiencia de una obra teatral o fílmica. Y es esta conexión la que hace de esta obra un objeto de estudio ideal para comparar coloquialidad en dos tipos de obra artística, la teatral y la fílmica, dado que es fundamental para el propio contenido de la obra en ambas versiones.

Para traspasar esta barrera que han encontrado los investigadores a la hora de analizar la coloquialidad en general, y en particular su aspecto sintáctico, proponemos un estudio interdisciplinario que, tomando como base el marco teórico propio de estudios sobre el español coloquial, aúne estudios literarios y lingǘsticos para conseguir un objetivo en común: descubrir qué procesos lingüísticos ha experimentado el texto en su adaptación cinematográfica. El estudio de la sintaxis coloquial cobra también gran importancia, puesto que, como reconoció Seco (1983), el grado más logrado de captación del habla coloquial en la escritura se vincula a la fidelidad con que se reproduce su peculiar sintaxis. Además, trataremos también el léxico de la obra de Alonso de Santos, por ser lo que 
el público percibe más conscientemente como señalador de registros y estilos, y lo que el autor o el director/guionista pueden también manipular más conscientemente.

El método seguido en el estudio del lenguaje coloquial en Bajarse al moro ha consistido en la transcripción de ambos textos, teatral y cinematográfico, y en el etiquetado de rasgos lingüísticos -que serán posteriormente descritos- con la intención de medir la frecuencia de aparición de estos rasgos de forma individual en cada uno de los textos y personajes, para luego compararlos entre sí y determinar, de forma cuantitativa, cuál de los textos presenta una mayor coloquialidad. La pregunta principal del estudio es: ¿qué texto presenta más rasgos coloquiales? Partimos de la hipótesis de que el texto cinematográfico es más coloquial que el dramático y comprobamos esta hipótesis mediante la comparación de rasgos de coloquialidad entre escenas de los dos textos.

\section{El LENGUAJE EN LAS ADAPTACIONES CINEMATOGRÁFICAS DEL TEATRO}

Una de las cuestiones principales que contemplaremos en este estudio son las diferencias discursivas entre el texto teatral y el fílmico, las cuales han sido ampliamente discutidas en muchos manuales sobre la adaptación.

En primer lugar, se ha debatido si el texto fílmico acepta el lenguaje estilizado que puede observarse en algunas obras dramáticas, sin que el público sienta cierto rechazo ante sus diálogos (Malpartida Tirado, 2006). Hay cierta tendencia a pensar que el diálogo cinematográfico se presenta «sin proliferación de sinónimos, sin un uso culto de figuras retóricas, desprovisto del cuidado estilístico de la lengua que implicaría la palabra escrita» (Wolf, 2001: 56). No obstante, como propone Malpartida Tirado, el uso de un lenguaje más o menos retórico puede quedar justificado dependiendo de «las reglas del juego» que sigue la obra en cuestión (2006: 197-199), y estas reglas tienen que ver con la situación comunicativa en la que se producen los intercambios dialogales. McKee afirma lo siguiente a este propósito:

La cámara y el micrófono magnifican y amplifican los comportamientos de tal manera que cualquier mirada falsa, cualquier gesto poco creíble, cualquier frase afectada parece y suena más de aficionados que la peor de las adivinanzas de una cena entre amigos. La interpretación en el cine exige una técnica naturalista, creíble y aparentemente improvisada. Para que esto sea posible, el diálogo para la pantalla debe parecer espontáneo (2016: 91).

Habría que preguntarse entonces: ¿se permite este lenguaje totalmente desprovisto de recursos retóricos y cuidado estilístico en piezas teatrales? Bajarse al moro demuestra esta posibilidad con su utilización de un lenguaje natural, sencillo y acorde al contexto en el que se enmarca, el de jóvenes que hablan de temas cotidianos $-\mathrm{y}$ no tan cotidianos-, en un entorno 


\section{Juan García-Cardona e Irene Checa-García}

amistoso y familiar. Sobre el lenguaje utilizado en Bajarse al moro se ha dicho que «es el vivo lenguaje de la calle el que articula el verbo dramático recorriendo la obra de comienzo a final» (Tamayo y Popeanga, 2019). Y resulta clara la utilización de un estilo coloquial ya en su versión dramática de acuerdo con el contexto de los personajes, una corriente que el propio José Luis Alonso de Santos (1999) enuncia en La escritura dramática: «en el teatro contemporáneo, una constante para muchos de los autores ha sido la intención de erradicar el habla "literaria" que se había instalado en los escenarios en el siglo XIX», a lo que añade más adelante: «la escritura dramática está conectada, pues, con el lenguaje del tiempo del escritor» (1999: 338-339).

Si bien los dos medios parecen partir de un texto escrito que va a ser representado, podríamos decir que ambos textos pertenecen a diferentes esferas, como ya señaló Pérez Martínez: «al defender el cine como texto audiovisual recordamos la distinción realizada por Van Dijk entre texto literario, donde situaríamos el teatro, y texto natural, donde encontramos el cine» (2004: 28). No obstante, ambos textos comportan una oralidad fingida $\mathrm{u}$ oralidad prefabricada, términos esgrimidos por Brumme y que ha definido como «un determinado tipo de oralidad que crea o configura un escritor o escritora para otorgar verosimilitud a los hechos que se exponen o los personajes que toman la palabra» (2008: 22).

Se trata de un concepto que ya han tratado los estudiosos del español coloquial, como Briz (1998) y Narbona (2001), y que han denominado oralidad literaria. Es, en definitiva, «un lenguaje escrito con la finalidad de ser dicho o pronunciado como si no hubiera sido escrito, es decir, como si realmente fuera un discurso oral» (Chaume, 2003: 102) ${ }^{1}$. Por ello, se incluirán rasgos lingüísticos que intenten simular esta oralidad en una búsqueda de un diálogo acorde con el personaje que suene natural -y real, como consecuencia- al espectador.

Esta definición incluiría todo tipo de diálogos, ya sea en una obra narrativa, dramática o audiovisual. No obstante, es en aquellos textos que se han concebido para su representación donde más se refleja este tipo de oralidad: «en condiciones normales un autor o autora concibe la obra en el medio gráfico siendo consciente, sin embargo, de su futura representación fónica» (Brumme, 2008: 22). Alonso de Santos discutió el tema en su manual sobre la creación dramática, en el que afirmó, con gran

\footnotetext{
${ }^{1}$ Algunos autores han afirmado que otro de los factores que determina el estilo de un hablante puede ser el medio por el que se produce la comunicación, es decir, si es oral o escrita (Wardhaugh y Fuller, 2014). No obstante, no debe confundirse el estilo que un hablante escoge intencionadamente de acuerdo con una determinada situación comunicativa frente al medio en el que se establece tal situación: no todo lo coloquial es oral ni todo lo escrito es formal.
} 
acierto, que «durante la representación teatral [...], el texto escrito de la obra "regresa" (por decirlo de modo gráfico) a la oralidad originaria» (1999: 335).

Esta «oralidad fingida» nos permite ahora construir otro término sobre el concepto de coloquialidad que nos atañe en este estudio. Al igual que ocurre con la oralidad en obras artísticas, no se trata de un lenguaje puramente coloquial, sino de un lenguaje construido para que sea coloquial y además funcione en dicha obra. La cuestión del lenguaje se ha tratado en numerosos manuales sobre la confección de guiones; por ejemplo, McKee afirma que «la forma de hablar cotidiana suena en pantalla torpe y como de aficionados» (2016: 151), y, además, que «la charla en la vida real se repite como el pepino [...] las conversaciones cotidianas carecen de intensidad, brillo, expresividad y, lo más peligroso, relevancia» (2016: 129). Por tanto, el autor no debe limitarse a transcribir conversaciones procedentes de su experiencia para confeccionar diálogos con rasgos lingüísticos coloquiales, sino que debe escudriñar y seleccionar dichos rasgos de forma adecuada.

La acuñación tomada por Brumme, a pesar de ser conveniente, incluye los términos «fingida» y «prefabricada», que, si bien representan esa noción de crear un texto que simula la oralidad, o la confección previa de un lenguaje que no es espontáneo, de forma respectiva, no recogen la intencionalidad del texto diseñado por la que sus rasgos son seleccionados de forma acorde al personaje, su demografía y la situación comunicativa en la que está inmerso, de manera que se obtiene como resultado una «coloquialidad moldeada». Este concepto denomina un tipo de lenguaje que no pretende ser una copia de ese lenguaje coloquial, sino el resultado de un proceso largo y muy elaborado por parte del autor.

No es la intención de este artículo describir esta «coloquialidad moldeada», si bien hemos podido observar la presencia de ciertos rasgos lingüísticos y su variación en ambos textos, pero sí la de proponer a nuevos investigadores que intenten describirla mediante casos concretos en una labor de inducción por la que sí se pueda llevar a cabo un modelo tipológico de formas de modelar la coloquialidad, ya sea en cine o en teatro, o en otras formas artísticas que requieran de esta simulación. En Bajarse al moro podemos observar cómo Alonso de Santos moldea un lenguaje que encaja a la perfección con los personajes a los que corresponde, evitando cierto caos y desorden que sucede sin problema en la cotidianeidad pero que, probablemente, presentaría dificultades en su entendimiento o incluiría elementos banales, redundantes o innecesarios en una obra con límites muy específicos en su extensión y que imponen delimitaciones a su discurso. 


\section{Juan García-Cardona e Irene Checa-García}

\section{EL MOTOR DE CAMBIO EN EL PROCESO DE ADAPTACIÓN DE TEATRO A CINE: LA NATURALIZACIÓN}

Proponemos ahora, como punto de partida, que el motor principal que propicia el cambio lingüístico de lo teatral a lo cinematográfico es un proceso de naturalización del lenguaje. El espectador o la espectadora entra en el teatro consciente de que se trata de una ficción, una especie de plano en dos dimensiones, limitado en extensión, con un único espacio escénico, con un tiempo presente que ocurre frente a él o ella. Por contra, la flexibilidad del cine, en cuanto a situación espacial, relaciones temporales e incluso efectos especiales, predetermina otro tipo de expectativas, hasta tal punto que escenas de cine más constreñidas y cuyo lenguaje suene más literario, puede ser percibidas como "teatrales". El afán por naturalizar el lenguaje plantea varias cuestiones, siendo la principal de ellas cómo conseguir esa naturalización.

Para obtenerla, se exploran muy diversos procedimientos en la construcción de los diálogos, como «la sustitución sinonímica por un vocablo, locución, expresión o sintagma más coloquial o no marcado», «la eliminación o reelaboración de expresiones metafóricas», o la «síntesis de turnos que agilizan el diálogo», entre otros muchos propuestos por Malpartida Tirado a propósito de una adaptación de Yerma (2006: 204-211), de manera que se dinamiza el intercambio comunicativo entre los personajes.

Otra característica que aporta naturalidad es la espontaneidad frente a la planificación, característica ampliamente debatida en los estudios sobre español coloquial (Beinhauer 1991; Briz, 1998). En los dos ámbitos, cine y teatro, la planificación es similar: parten de un texto escrito que los actores deben seguir. La espontaneidad se sitúa en un terreno movedizo en el caso de Bajarse al moro: si bien la función teatral es única y por tanto la espontaneidad sería mayor frente a las tomas repetidas del ámbito fílmico, las instrucciones del director Fernando Colomo a los actores fueron las de improvisación en ciertos casos, y afirmó en una entrevista para TVE que prefería rodar las escenas sin apenas ensayo para buscar una mayor naturalidad en su desarrollo (Colomo, 2013). Y es esta una de las cuestiones más discutidas en la adaptación al cine: «lo que se diga tiene que mantenerse dentro del terreno de lo interpretable. Esta exigencia nos lleva a una importante diferencia entre el diálogo para el escenario frente al de la pantalla: la improvisación» (McKee, 2016: 94).

Una tercera característica para lograr la naturalización es la verosimilitud. Pérez Bowie ya señaló su importancia: «las aproximaciones [del cine] al teatro suelen proceder llevando a cabo una naturalización a fondo del universo artificioso [...] y una eliminación de todos los elementos susceptibles de cuestionar la verosimilitud» (2008: 104). Además, José Luis Alonso de Santos remarcó la relación entre verosimilitud e historicidad: una obra verosímil en el siglo XIX no lo será, necesariamente, en nuestra 
La coloquialidad en la adaptación cinematográfica del texto teatral

época (1999: 337). La concepción de una obra verosímil se sustenta, en gran parte, en el uso de diálogos coherentes con la situación y los personajes que los mantienen, por lo que el lenguaje juega un papel fundamental en este aspecto: «de todas las facetas de la creación de un personaje, la palabra hablada es, con diferencia, la más susceptible de despertar la incredulidad» (McKee, 2016: 143).

En cuanto a las modificaciones que se producen del texto teatral al cinematográfico, los cambios in situ por necesidades actorales o logísticas, o por motivaciones variadas durante la grabación de un filme, sin dejar de asumir que, en su mayoría, son arbitrarios, y que también pueden producirse en la representación teatral, podrían tener cierta influencia en lo lingüístico. Debido a las limitaciones de los datos analizados y al desconocimiento de estas modificaciones más allá de comentarios esporádicos del director en alguna entrevista, no se tendrán en cuenta estos cambios efectuados en el rodaje de la película; en todo caso, se percibirán indirectamente a través de sus efectos lingüísticos.

En definitiva, el texto teatral sufre un cambio lingüístico caracterizado por una búsqueda de verosimilitud, una simplificación de la lengua o de recursos literarios y una mayor espontaneidad de los actores, buscando con todo ello lograr una mayor naturalización en su adaptación al cine. Los mecanismos de este cambio, manifestados lingüísticamente, son lo que este estudio quiere determinar, para lo cual se hace imprescindible un análisis lingüístico minucioso y riguroso. Distintos textos comportarán distintas características: es ahora nuestra tarea clasificar estos cambios en el ámbito de lo lingüístico.

\section{RASGOS DEL ESPAÑOL COLOQUIAL}

En esta sección se definirá el español coloquial como concepto general, haciendo hincapié en aquellos rasgos que se contemplarán en este estudio. El lenguaje utilizado por un hablante puede cambiar por diferentes motivos: entre otros, el contexto en el que se encuentra inmerso o la intención que posea tal hablante. La adecuación del uso lingüístico a una serie de factores contextuales que condicionan la situación comunicativa recibe el nombre de registro ${ }^{2}$. Estos factores tienen un efecto lingüístico determinado; uno de los más importantes es el de la formalidad, un concepto amplio y difícil de definir: «la formalidad [...] incluye muchos factores como la situación, la

\footnotetext{
${ }^{2}$ Hay cierto debate sobre esta denominación: mientras que algunos investigadores consideran el lenguaje coloquial como un registro (Beinhauer, 1991; Briz, 1998), en los manuales de sociolingüística de autores como Trudgill (2000) o Wardhaugh y Fuller (2014), lo coloquial parece responder a la definición de estilo más que de registro. En este trabajo hemos optado por concebirlo como registro.
} 


\section{Juan García-Cardona e Irene Checa-García}

familiaridad social, la relación de parentesco entre los interlocutores, la cortesía, la seriedad y más» (Trudgill, 2000: 82) . $^{3}$

Según Beinhauer, «entendemos por lenguaje coloquial el habla tal como brota, natural y espontáneamente en la conversación diaria, a diferencia de las manifestaciones lingüísticas conscientemente formuladas» (1991: 9). Como ya hemos visto, se atribuyen distintas características a este registro del lenguaje, tales como la familiaridad, la cotidianidad, la identificación de este estilo con un tono informal, su gran expresividad y su componente subjetivo, un léxico peculiar no especializado que dista de los registros estrictamente formales y la utilización de expresiones familiares de diversos tipos.

El uso del registro coloquial está caracterizado por ciertos hechos lingüísticos verbales y extraverbales (fónicos, morfológicos, sintácticos, léxico-semánticos, de carácter gestual, etc.), que son lo que Briz (1996 y 2011) denomina constantes de dicho registro. Y todos estos hechos aparecen vinculados entre sí con la misma finalidad, tanto los hechos lingüísticos como los extralingüísticos y los paralingüísticos, en los que subyace una misma estrategia que comportará unas constantes determinadas según la intencionalidad.

\section{CaraCterización lingüística de BaJARSE AL MORO}

\subsection{Delimitación de variables}

Algunos rasgos lingüísticos de Bajarse al moro ya han sido estudiados anteriormente (Hernando Cuadrado, 2001; Tamayo y Popeanga, 2019), sobre todo los aspectos fonéticos y léxicos. A propósito de los primeros, se ha señalado la pérdida de fonemas, como la /d/ intervocálica en palabras como degeneraos, proceso fonológico propio de ciertos dialectos considerados habitualmente lengua "menos estándar". Se ha destacado también, en cuanto al vocabulario, el empleo de las formas apocopadas frente a las primitivas: la poli, el chomi o el cole, entre otras; y la sufijación con matiz atenuante y festivo, como muslamen. En lo semántico, estos autores han observado la presencia de una gran cantidad de vocablos con doble sentido y cargados de nuevas acepciones, algunas de ellas recogidas como vulgares por la Academia, como harina, china o chocolate.

Como ya hemos mencionado, en este estudio contemplaremos únicamente variables léxicas y sintácticas. Seco ha defendido una tendencia centrífuga en la sintaxis coloquial, caracterizada por una falta de conectores y formada por una serie de enunciados que rechazan una estructura orgánica. Se trata de una construcción de oraciones segmentada, donde predomina la hipotaxis, y a colación de esta tendencia centrífuga

\footnotetext{
${ }^{3}$ Traducción de los autores.
} 
dice que las oraciones «carecen de un centro magnético que los engarce en una oración unitaria» (1973: 370). Para caracterizar el lenguaje coloquial y poder comparar dos obras en términos de su coloquialidad, se hace necesario definirla de forma más precisa que con términos como «centro magnético» o «tendencia centrífuga», así como usar unidades de comparación susceptibles de ser computadas. Con tal fin, exponemos a continuación estas unidades, definiéndolas y explicando brevemente su conexión con la coloquialidad:

a) Tuteo frente al uso de usted (Navarro, 1996-97). Un mayor uso del tratamiento de tú es la marca más directamente vinculada (hasta el punto de ser marca gramatical) con la informalidad comunicativa en español. Este uso es propio de situaciones informales o entre "iguales", en las que los interlocutores mantienen algún tipo de relación amistosa o familiar, si bien la diferencia de edad puede ser un factor también. En cualquier caso, un mayor empleo de la forma usted se relaciona usualmente con un registro formal en lugar de coloquial.

b) Uso de la primera y segunda persona (Briz, 1996). Una mayor proporción de primera y segunda persona frente a la tercera es característica de la conversación -frente otros géneros como el monólogo, la conferencia, la narración, etc.-, puesto que se tiende a hablar de uno mismo y de la persona con la que se establece el intercambio comunicativo más que de otras personas no presentes. Al ser característica de la conversación, se asocia también con un registro coloquial.

c) Redundancia (Narbona, 1989). La redundancia engloba a la repetición (utilización de las mismas palabras) y a la reelaboración (en la que las palabras exactas no se repiten pero el mensaje sí). En un registro más formal, las redundancias son percibidas como ineficientes e innecesarias. En la conversación, por contra, estas son formas de ayudar a una recepción del mensaje (y en el caso de la reelaboración, para aclararlo), o de compensar por problemas de percepción extralingüísticos (ruidos externos, problemas de audición del receptor, etc.), o simplemente de indicar solidaridad, al repetir lo que dijo nuestro interlocutor, etc. De nuevo, la asociación de la redundancia a tipos de intercambios comunicativos propios de situaciones informales, como la conversación, lleva a su inclusión entre las características de la coloquialidad.

d) Complejidad sintáctica, bien indicada por varios autores como ausencia de hipotaxis (subordinación), o bien no especificada (Briz, 1996). Para este trabajo utilizaremos índices de complejidad sintáctica ampliamente usados en la determinación 


\section{Juan García-Cardona e Irene Checa-García}

de la complejidad sintáctica, sobre todo de textos (Hunt, 1964), e incluso para caracterizar diferencias entre géneros (Véliz, 1999). Emplearemos aquí solo los tres índices primarios: longitud de la unidad terminal (número de palabras por unidad terminal) ${ }^{4}$, longitud de cláusula (número de palabras por cláusula) $)^{5}$ e índice de subordinación (número de cláusulas por unidad terminal). Textos más informales son habitualmente caracterizados como menos complejos sintácticamente, si bien, como dijimos, cómo ocurre esto exactamente y cómo determinar su grado de complejidad no es especificado en trabajos previos.

e) Los enunciados suspendidos (Herrero Moreno, 1997), oraciones cuyo mensaje se ve completado por el contexto en el que se utilizan, pero que están incompletas, tanto semánticamente como sintácticamente, y que denominaremos oraciones incompletas, como No sé yo si..., Bueno, eso no es..., de nuevo más frecuentes, en principio, en textos más coloquiales.

f) Los enunciados averbales, dotados de sentido completo pero en los que no hay verbo, como ¿Qué tal? o ¡Qué barbaridad! Los enunciados averbales están casi desterrados de registros formales y tienen una fuerte connotación coloquial.

g) Oraciones insubordinadas, que contienen características de subordinación pero que carecen de un verbo principal: Que vengas aquí vs. Te digo que vengas aquí (Evans y Watanabe, 2016). Estas oraciones son rechazadas desde un punto de vista de la gramática normativa pero ocurren con frecuencia en la conversación cotidiana, por lo que podrían usarse como excelentes marcas de la coloquialidad en español.

Una variable que ha sido ampliamente usada, pero que no incluiremos aquí, es la de la proporción de estilo directo (Me dijo: "ven aqui") vs. estilo indirecto (Me dijo que fuera alli). Tradicionalmente se ha señalado que el estilo directo es más frecuente en la coloquialidad y menos preferido en registros más formales (Briz, 1996). No obstante, tanto teatro como cine son ámbitos en los que la mayoría del lenguaje se encauza en forma de diálogo. En este formato, la frecuencia con que se reportan las palabras de otros es muy pequeña, siendo lo habitual que este reporte no sea necesario y los hablantes, simplemente, hablen ellos mismos. De hecho,

\footnotetext{
${ }^{4}$ Verbo principal más todo lo que depende de él. Así, oraciones coordinadas y yuxtapuestas constituyen cada una su unidad terminal. Para una definición más precisa y una adaptación de la unidad al español, véase Checa-García (2005).

${ }^{5}$ Verbo más todo lo que depende de él, excluidas las perífrasis, pero no otras formas impersonales (véase de nuevo Checa-García, 2005, capítulo 2, sección 7).
} 
computamos la frecuencia de ambos estilos y esta resultó cero o uno para ambos en todas las escenas, salvo en una escena del texto teatral que consistió en un monólogo de Jaimito, uno de los personajes principales. Por tanto, parece más adecuado omitir proporción entre estilo directo e indirecto como un índice de coloquialidad dada la escasez de ambos estilos.

A diferencia de la vertiente sintáctica, el léxico de Bajarse al moro ha sido descrito en los artículos antes mencionados, en especial respecto a los campos semánticos, señalándose la presencia de numerosos vocablos referentes a la droga. En este estudio hemos seleccionado variables léxicas algo diferentes a las consignadas en esos estudios, y además las hemos computado. Ello nos permite comparar cuantitativamente y con mayor detalle tanto el guion fílmico como la obra teatral. De entre las consideradas en las investigaciones sobre coloquialidad en español, hemos incluido:

a) Las palabras comodín (Briz, 1997). Son palabras con significado muy amplio que pueden utilizarse en multitud de contextos pero con menor precisión semántica: eso, la cosa, etc.

b) El uso de argot perteneciente a clases sociales determinadas (Rodríguez, 2007). No debemos confundirlo con la jerga, que se refiere a una estratificación desde el punto de vista profesional, frente al argot, que queda delimitado por el ámbito social. En definitiva, el argot puede definirse como el lenguaje usado por los grupos sociales situados al margen de la sociedad, como es el caso de los delincuentes (Santamaría Pérez, 2001). El propio título de la obra, Bajarse al moro, pertenece al argot del mundo de las drogas, $\mathrm{y}$ otro ejemplo es la utilización de chocolate para denominar al hachís.

c) Las muletillas (Briz, 1998). Son palabras que se repiten sistemáticamente en el habla de ciertos individuos sin que tengan necesariamente su significado habitual. Un ejemplo sería la repetición de por consiguiente del ex-presidente del gobierno español Felipe González.

d) Las metáforas (Briz, 1998), pero solo las convencionalizadas. Estas son metáforas que se usan en la vida cotidiana, hasta tal punto que su valor metafórico no es percibido ya por los hablantes (Lakoff y Johnson, 1980): encogérsele a alguien el corazón, no llegarle a alguien la camisa al cuello, no tener sangre en las venas, etc. Contrastan con las metáforas literarias, desconocidas para el lector hasta que las lee y que pueden producir diversas interpretaciones al no estar convencionalizadas. 


\section{Juan García-Cardona e Irene Checa-García}

Se han incluido también algunas variables que no han sido tradicionalmente tratadas como características de lo coloquial, pero que en nuestra opinión se asocian con un registro informal:

e) Las interjecciones, palabras generalmente monótonas que expresan sentimientos y emociones (ay, bah, oh).

f) Colocaciones no composicionales, grupos de palabras que van usualmente juntas y en ese orden y que adquieren su significado conjunto por convención y no por la suma de sus valores, es decir, no composicionalmente, de forma que el significado de la expresión no puede deducirse de sus elementos individuales; por ejemplo, Te vas a enterar, No te jode o No me da la gana.

g) La diversidad léxica, que consiste en la proporción de palabras diferentes usadas por el total de palabras usadas (TracyVentura, 2017). La idea es que en un registro más coloquial se tiende a utilizar las mismas palabras, mientras que un registro más formal preocupado por la precisión léxica usará más palabras diferentes y específicas. Por tanto, una mayor diversidad léxica señalará una menor coloquialidad.

h) Palabras tabúes, que son consideradas vulgares o malsonantes. Discutimos a continuación el caso peculiar del lenguaje vulgar y su relación con la coloquialidad, en especial en Bajarse al moro.

\section{2. Lenguaje vulgar vs. lenguaje coloquial en Bajarse al moro}

El lenguaje utilizado en Bajarse al moro pone de manifiesto una intención del autor por poner en boca de los personajes un lenguaje vulgar de acuerdo con el sector social al que pertenecen, un sector marginal relacionado con las drogas. El lenguaje vulgar hace referencia a aquel que transgrede las normas sociales establecidas. Más aún, estos usos se asocian a una falta de formación o conocimiento por parte del hablante así como con estratos marginales dentro de la sociedad. Por tanto, los espectadores podrían conectar lo vulgar con lo coloquial e incluso con lo marginal, de manera que la presencia de rasgos lingüísticos vulgares daría la impresión de un lenguaje más coloquial, pero posiblemente también de hablantes de dicho lenguaje como pertenecientes a estratos sociales más marginales.

Como ya mencionamos en la introducción, la definición de lenguaje vulgar no se corresponde con la de lenguaje coloquial; no obstante, lo vulgar parece enmarcarse dentro de lo coloquial, si bien lo coloquial no necesita incluir vulgarismos por definición. Así, quizá la intención de Alonso de Santos era la de representar un lenguaje propio de una clase 
social marginal, inevitablemente relacionado con el vulgar, y para ello ha utilizado rasgos coloquiales y también vulgares, como las palabras tabúes ${ }^{6}$. Según el propio autor, «cuando escribí Bajarse al moro, por ejemplo, dada la situación un tanto marginal de sus personajes, intenté que los diálogos se basaran en un argot situado en las fronteras de la lengua» (1999: 314). Por tanto, el uso de vulgarismos obedece en la versión original teatral a un deseo de enmarcar a los personajes en un cierto contexto social según el propio autor, pero su posible aumento en el cine podría tener además el objetivo de la naturalización del lenguaje haciéndolo más coloquial aún.

No obstante, otros estudiosos han señalado que el lenguaje vulgar podría de hecho indexar más a una generación que a un estrato social. Así, Tamayo y Popeanga afirman que «el empleo de este tipo de lenguaje se extiende, con mucho, más allá de un sector restringido del mundo social, llegando a cobrar un alcance generacional», y sobre la interacción de este lenguaje y los personajes, añaden que «podía haberse puesto en boca de cualesquiera otros personajes cuyos prototipos procediesen de las más heterogéneas capas sociales» (2019: 71). Esta interpretación cobra aún más sentido si pensamos en el contexto histórico de Bajarse al moro dentro del movimiento de teatro independiente de la época y sobre todo en el contexto cultural de la movida, en el que transgredir las normas - por ejemplo, hablando de temas tabúes o cuestionando instituciones hasta entonces sagradas- era casi deber de ciudadano rebelde. Se ha señalado que en Bajarse al moro se presenta a esta clase marginal como más sincera y menos hipócrita. El lenguaje que usan, transgresor, ayuda también a distanciarlos de esas otras generaciones más tradicionales, o acaso clases, dado que los personajes de Elena y Alberto, también jóvenes, acaban pasando a ese lado tradicional e hipócrita de la sociedad.

En definitiva, un texto vulgar es siempre coloquial, pero uno coloquial no siempre es vulgar. Bajo el concepto de coloquialidad podemos distinguir como una de sus características la presencia de rasgos vulgares, por lo que hemos decidido codificar este aspecto entre nuestras variables.

\subsection{Análisis de rasgos coloquiales en la obra teatral y la fílmica}

Para poder computar cada una de las variables de la coloquialidad que hemos considerado, hemos seleccionado seis escenas de la obra teatral con

\footnotetext{
${ }^{6}$ Una interesante cuestión lingüística, que no trataremos en este artículo, sería la elaboración de un espectro formal-informal en el que el lenguaje vulgar poseería los rasgos propios de la coloquialidad llevadas al extremo, lo que justificaría que al intentar quedarse en estas fronteras se haya conseguido la coloquialidad analizada anteriormente.
} 


\section{Juan García-Cardona e Irene Checa-García}

sus correspondientes escenas en la película. La tabla 1 muestra las correspondencias seleccionadas:

Tabla 1. Correspondencia de escenas teatrales y fílmicas seleccionadas

\begin{tabular}{|l|l|l|l|l|l|l|}
\hline Acto & \multicolumn{3}{|c|}{ Primero } & \multicolumn{3}{c|}{ Segundo } \\
\hline Teatro & Escena 1 & Escena 2 & $\begin{array}{l}\text { Escena } \\
4\end{array}$ & $\begin{array}{l}\text { Escena } \\
1\end{array}$ & $\begin{array}{l}\text { Escena } \\
2\end{array}$ & Escena 3 \\
\hline Cine & $\begin{array}{l}\text { Escenas 6 } \\
\text { y 7 }\end{array}$ & $\begin{array}{l}\text { Escenas 12, } \\
14 \text { y 15 }\end{array}$ & $\begin{array}{l}\text { Escena } \\
19\end{array}$ & $\begin{array}{l}\text { Escena } \\
22\end{array}$ & $\begin{array}{l}\text { Escena } \\
33\end{array}$ & $\begin{array}{l}\text { Escenas 37 } \\
\text { 40 }\end{array}$ \\
\hline
\end{tabular}

A continuación, hemos procedido a etiquetar cada instancia de cada una de las variables. Una vez etiquetado así nuestro corpus de escenas, procedimos a contabilizar el número de instancias de cada variable en cada escena de teatro y en cada escena de cine. Contrastamos entonces las frecuencias de estas variables en teatro y cine mediante el uso de la mediana. Optamos por la mediana como resumen de la tendencia central de cine y teatro debido al escaso número de observaciones para cada uno, seis, y debido a que la media es demasiado sensible a valores extremos. Las figuras 1 a 4 reflejan la diferencia entre las medianas de cine y teatro para diferentes grupos de variables: complejidad sintáctica, rasgos sintácticos, persona y rasgos léxicos. El color más oscuro corresponde al teatro y el gris claro al cine. Los valores de la mediana aparecen recogidos en la parte superior de cada barra.

Figura 1. Complejidad sintáctica en teatro vs. Cine

$$
\text { - Teatro } \quad \text { Cine }
$$

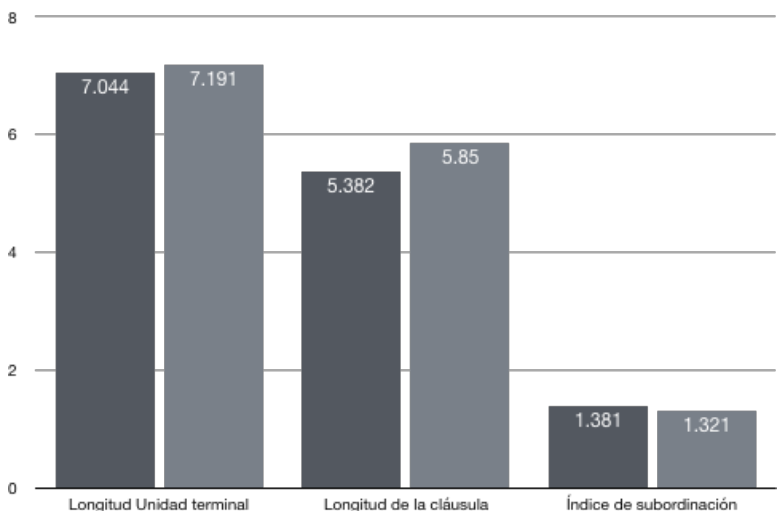


Como puede observarse en la figura 1, en teatro hay mayor subordinación, pero la longitud de las cláusulas es menor. La longitud de la unidad terminal, que resulta de multiplicar ambas, es algo mayor para el cine. Es decir, en el teatro la longitud de las oraciones aumenta porque hay más oraciones dentro de otras, más subordinación, mientras que en el cine las cláusulas tienen más palabras, pero hay menos subordinación. Las diferencias son pequeñas y, de hecho, tras aplicar el test no paramétrico para medidas dependientes que compara los resultados de cada escena teatral con su correspondiente en el cine $^{7}$, ninguna de las diferencias en complejidad sintáctica resultó significativa. Por tanto, la complejidad sintáctica no es un rasgo de mayor coloquialidad en el cine vs. el teatro, al menos para el caso de Bajarse al moro.

Figura 2. Rasgos sintácticos en teatro vs. Cine

Teatro Cine

0.3

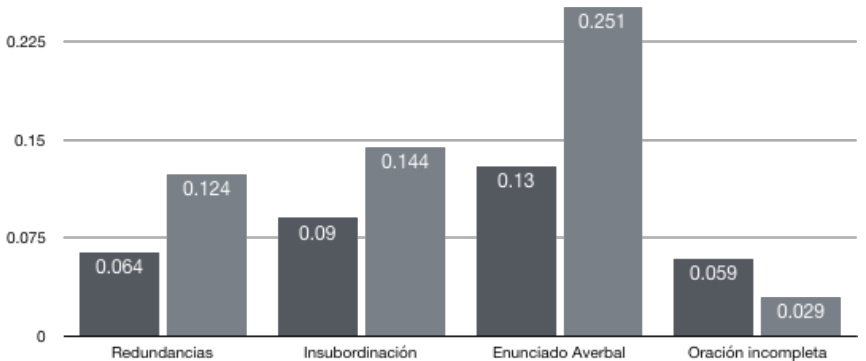

Repeticiones y reelaboraciones se han sumado para constituir la categoría de redundancias. Como puede verse, hay casi el doble de redundancias en el cine que en el teatro. También la insubordinación es mayor en el cine que en el teatro. La mayor diferencia entre las medianas se da en el número de enunciados averbales, donde el cine duplica al teatro. Finalmente, las oraciones incompletas ocurren más frecuentemente en el teatro, única variable de la figura que es mayor en el teatro, aunque esta diferencia es una de las menores, junto con la de insubordinación. El test de significatividad reveló, no obstante, que solo la cantidad de enunciados averbales fue significativamente más alta en el cine $(\mathrm{p}=0,028)$.

\footnotetext{
${ }^{7}$ Se utilizó la prueba de Wilcoxon (1945), puesto que las asunciones de normalidad y/o homocedasticidad no se cumplieron y porque el tamaño muestral era pequeño.
} 
Juan García-Cardona e Irene Checa-García

Figura 3. La persona gramatical en la película y en la obra teatral

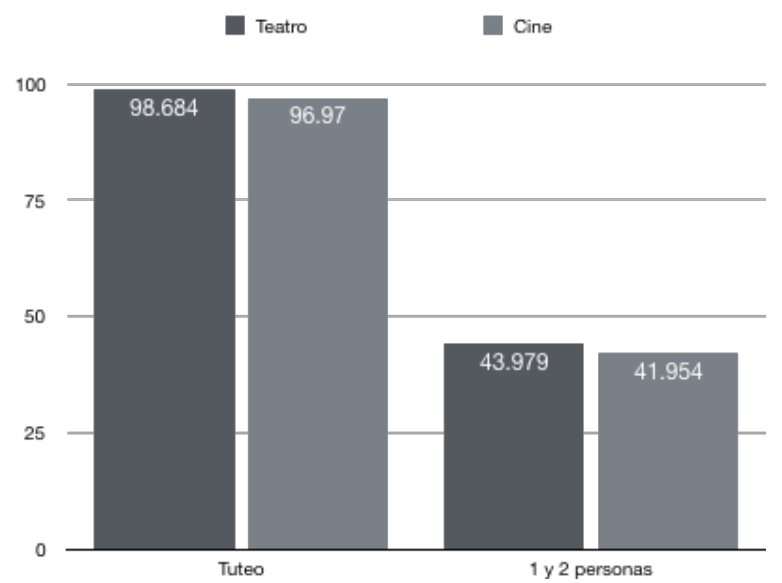

Tanto el tuteo como la proporción de primera y segunda persona (vs. tercera) son muy similares en la versión teatral y la fílmica. La escasa diferencia no resultó estadísticamente significativa.

Figura 4. Rasgos léxicos en la versión teatral vs. la fílmica

Teatro

cine

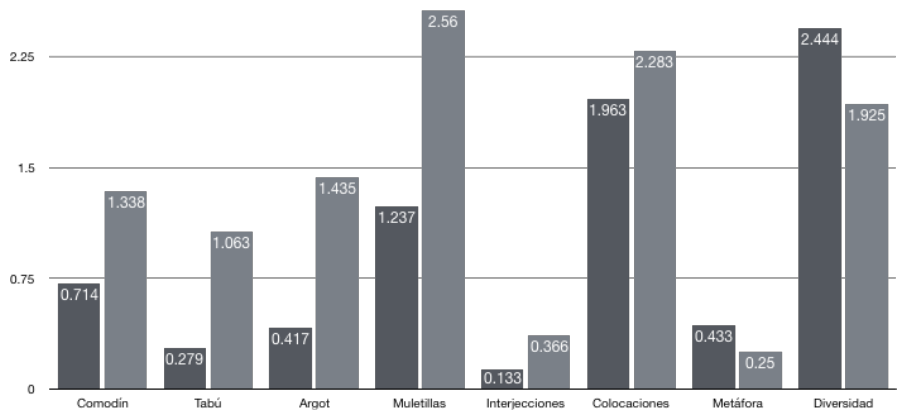

Lo más notable de la figura 4 es que en todos los casos el cine muestra valores más altos, salvo para la metáfora convencional y la diversidad léxica, para la que el teatro muestra valores más altos. Las diferencias son muy 
grandes en el caso de las palabras comodín, las palabras tabúes, la jerga, las muletillas y las interjecciones en cuanto a la mediana. El test de significatividad reveló que las diferencias fueron significativas en las palabras comodín $(\mathrm{p}=0,046)$, las palabras tabúes $(\mathrm{p}=0,043)$ y las interjecciones $(\mathrm{p}=0,046)$.

\section{CONCLUSIONES: LOS MECANISMOS DE CAMBIO ENTRE AMBOSTEXTOS}

A la luz de estos resultados podemos concluir que la naturalización del texto fílmico hacia una mayor coloquialidad descansa fundamentalmente en rasgos léxicos y alguno sintáctico, mientras que no se debe ni a la menor complejidad sintáctica ni a un mayor uso del tuteo o de la primera y segunda personas. En cuanto a este último rasgo, debemos señalar que la naturaleza dialógica, tanto del teatro como del cine, hace probable un uso similar de la primera y segunda persona. El empleo del tuteo parece estar también gobernado en ambos casos, teatro y cine, por las reglas usuales del español, que lo determinan por la relación entre los personajes en la situación comunicativa. Dado que dicha relación es la misma en la versión teatral y en la fílmica, es de esperar un uso similar por parte de los mismos personajes ${ }^{8}$.

En cuanto a la complejidad sintáctica, se observa en el teatro una mayor subordinación, rasgo más típico del lenguaje escrito, pero la sintaxis parece un aspecto más automático del que el autor sería menos consciente y por tanto no usaría para dar un toque más o menos coloquial a los personajes. No obstante, sí hay ciertas diferencias sintácticas entre teatro y cine que señalan hacia una sintaxis más cuidada en general para el teatro que para el cine, apuntando a esa "espontaneidad" de la que hablábamos al principio, o incluso poca preocupación por la corrección del idioma, que apunta a un uso más vulgar y relajado para el caso del cine. Efectivamente, encontramos en la película más insubordinación, más redundancias y más enunciados averbales, y aunque esta diferencia solo sea estadísticamente significativa para los enunciados averbales, son bastante grandes para las tres variables. Muchos casos de redundancias y muchos de los enunciados averbales, así como todos los casos de insubordinación, son instancias de usos lingüísticos sancionados como incorrectos gramaticalmente y que por tanto pintan a sus usuarios como más despreocupados por la corrección gramatical e incluso pertenecientes a un estrato social más bajo debido a las asociaciones que antes comentábamos. Además, en el caso de la insubordinación y los enunciados averbales, estos suelen conducir a una

\footnotetext{
${ }^{8}$ En algunas escenas de la película había más personajes, que podrían acaso haber variado su uso del tú y el usted. Sin embargo, las escenas con personajes extra no fueron mayoritarias, y estos nuevos personajes usaron de forma similar tú/usted, o bien las diferencias no fueron suficientes o consistentes (en la misma dirección siempre) para tener un peso cuantitativo.
} 


\section{Juan García-Cardona e Irene Checa-García}

mayor rapidez y fluidez en las intervenciones, dado que con frecuencia reducen su extensión, ya sea obviando el verbo principal (insubordinación) u obviando el verbo en el enunciado (enunciados averbales). Hay un modo de acortamiento de las oraciones, sin embargo, que parece no preferirse en el cine frente al teatro: las oraciones incompletas, oraciones truncadas solo al final. Será necesario un estudio de más casos (otras escenas y otras obras) y un análisis de tipos de truncación, para averiguar a qué se debe esta diferencia. Por ejemplo, tal vez algunos de los enunciados incompletos o truncados en el teatro sean retomados y completados por otro personaje, y tal vez este tipo de oración incompleta no suceda en el cine, siendo entonces que se terminaría el enunciado o un cierto sentido en el teatro pero no en el cine. En cualquier caso, las oraciones incompletas necesitarán de una investigación más detallada para explicar su aparente estatus especial en lo que a teatro vs. cine corresponde.

Finalmente, el conjunto de rasgos que han resultado más diferenciadores de la coloquialidad han sido los elementos léxicos que hemos considerado en el estudio. Todos ellos se han alineado con nuestras predicciones de que su número sería mayor o menor de acuerdo con su contribución a una mayor coloquialidad en el cine con la excepción de las metáforas convencionales. Es interesante anotar aquí la similitud entre metáforas convencionalizadas, que hacen que incluso las acepciones de los verbos implicados se amplíen para añadir significados más metafóricos en el diccionario para esa entrada, y las colocaciones, que si bien no extienden los significados de las palabras contenidas, sí que, al igual que las metáforas convencionales, no son composicionales. Es posible que aquí la diferencia se encuentre precisamente en que las metáforas convencionales extienden el significado de sus componentes y de que lo hacen con una cierta lógica, por una cierta analogía usualmente, vs. una expresión simplemente fosilizada cuyo origen o significado original ya no se puede rastrear. Por qué es el caso que esta "rastreabilidad" no conduce a representar usos más coloquiales y abunda más, aunque no significativamente, en el teatro, es una pregunta cuya respuesta requiere de más datos y más investigación cualitativa para formular posibles hipótesis/respuestas. Salvo las metáforas, como decimos, todos los rasgos léxicos se comportan como esperábamos, y palabras comodín, tabúes, jerga, muletillas, interjecciones y colocaciones, aumentan en el cine paralelamente a su conexión con la coloquialidad, de manera que contribuirían a hacer la pieza fílmica más coloquial que la versión teatral. La diversidad léxica, relacionada inversamente con la coloquialidad, es menor en el cine que en el teatro, de nuevo haciendo al cine más coloquial. De estas variables tres fueron estadísticamente significativas: comodines, tabúes y jerga. Las dos últimas especialmente se relacionan con un lenguaje más vulgar y parecen decisivas en la representación de personajes del hampa, donde el cine parece hacer más hincapié. 
Así pues, puede concluirse que el cine es más coloquial que el teatro y que obtiene su mayor coloquialidad sobre todo de rasgos léxicos y de una cierta dejadez sintáctica, si bien no de una menor complejidad sintáctica ni tampoco del uso de las diferentes personas gramaticales. Esto no quiere decir que la pieza teatral de Bajarse al moro no sea coloquial, puesto que para decir esto deberíamos comparar las medidas con ciertos estándares provenientes de géneros y situaciones comunicativas eminentemente coloquiales, como conversaciones entre amigos, y aún no se han elaborado tales estándares. Pero sí quiere decir que, en comparación con su versión fílmica, es ciertamente menos coloquial que esta.

Estos cambios pueden haberse debido, en parte, a lo que comentábamos acerca de la posibilidad dada a los actores de cine para improvisar, y en particular a la que Fernando Colomo, el director, declaró que dio a sus actores, en la línea de lo indicado por McKee:

En teatro, el dramaturgo posee los derechos de sus obras. El resultado es que los actores no pueden improvisar o alterar el diálogo sin permiso del autor. En cine y televisión, por el contrario, el escritor cede los derechos a la productora, de manera que cuando es necesario, los directores, los montadores y los actores pueden cortar, modificar o añadir diálogo (2016: 95).

Es este el cambio principal que se puede registrar en el proceso de adaptación: el director goza de mayor libertad a la hora de transformar el texto, lo que implica también una mayor naturalidad y espontaneidad en el proceso. Esta espontaneización del texto dramático da lugar a una mayor presencia de rasgos coloquiales, incluidos los propios de producciones orales, que han podido estudiarse mediante el estudio cuantitativo que proponíamos en el apartado anterior. El resultado es un texto más espontáneo y natural que acaso resulta más verosímil para el espectador, para lo que se han manipulado rasgos léxicos (jerga, comodines, tabúes y posiblemente también interjecciones, muletillas, colocaciones y diversidad léxica) y sintácticos (enunciados averbales y posiblemente insubordinación y redundancias).

Nuestros resultados arrojan también nuevas cuestiones que podrían abordarse en futuras investigaciones. ¿Por qué es diferente el comportamiento de oraciones incompletas al de enunciados averbales e insubordinación? Y, ¿cómo son diferentes las colocaciones de las metáforas convencionales y por qué estas parecen más frecuentes en el teatro? Además, se hace necesario investigar otras adaptaciones para corroborar los resultados de este estudio, parcialmente limitado por el número de escenas analizadas. Confiamos, no obstante, en que este trabajo anime a otros investigadores a analizar más datos con esta y otras metodologías 


\section{Juan García-Cardona e Irene Checa-García}

cuyos resultados puedan contrastarse con este estudio y llevar a una visión más completa de los procesos que tienen lugar en las adaptaciones al cine de diversas obras literarias.

\section{BibliografíA CITADA}

Alonso De SAntos, José Luis (1999), La escritura dramática, Madrid, Castalia.

BeINHAUER, Werner (1991), El español coloquial, Madrid, Gredos.

BRIZ, Antonio (1996), El español coloquial: situación y uso, Madrid, Arco/Libros.

BriZ, Antonio (1997), «Coherencia y cohesión en la conversación coloquial», en M. Iglesias (coord.), Gramma-temas. 2, Universidad de León, págs. 9-44.

BRIZ, Antonio (1998), El español coloquial en la conversación: esbozo de pragmagramática, Barcelona, Ariel.

BRumme, Jenny (2008), «Traducir la oralidad teatral. Las traducciones al castellano, catalán, francés y euskera de Der Kontrabass de Patrick Süskind», en J. Brumme (ed.), La oralidad fingida: descripción y traducción. Teatro, cómic y medios audiovisuales, Madrid/Frankfurt am Main, Iberoamericana/Vervuert Verlag, págs. 21-64.

Chaume, Frederic (2003), Dotblage i subtitulació per a la TV, Vic, Eumo.

CheCA García, Irene (2005), Índices de madurez sintáctica en adolescentes almerienses, Universidad de Almería.

Colomo, Fernando (2013), Coloquio sobre Bajarse al moro. Versión española (TVE) [En línea: http://www.rtve.es/alacarta/videos/versionespanola/version-espanola-bajarse-moro/1665283/]

Evans, N., \& WATANABE, H. (Eds.) (2016). Insubordination. Amsterdam/N.Y: John Benjamins Publishing Company.

Hernando Cuadrado, Luis Alberto (2001), «El registro coloquial en Bajarse al moro, de J. L. Alonso de Santos», Cuadernos para investigación de la literatura hispánica, 26, págs. 145-154.

Herrero Moreno, Gemma (1996), «La importancia del concepto de enunciado en la investigación del español coloquial: a propósito de enunciados suspendidos», en A. Briz et al. (eds.), Pragmática y gramática del español hablado. Actas del II Simposio sobre análisis del discurso oral, Zaragoza, Libros Pórtico, págs. 109-126.

Hidalgo Navarro, Antonio (1996-1997), «Sobre los mecanismos de impersonalización en la conversación coloquial: el tú impersonal», E.L.U.A., 11, págs. 163-176 [En línea: http://rua.ua.es/dspace/handle/10045/6353].

HunT, Kellogg W. (1964), Differences in grammatical structures written at three grade levels, the structures to be analyzed by transformational methods, Tallahassee, Florida State University. 
La coloquialidad en la adaptación cinematográfica del texto teatral

LakofF, George y Mark Johnson, (1980), Metaphors we live by, Chicago, University of Chicago Press.

Malpartida Tirado, Rafael (2006), «Del diálogo dramático al diálogo fílmico: una propuesta de estudio», en Analecta Malacitana, XXIX/1, págs. 197-214.

McKeE, Robert (2018), El diálogo. El arte de hablar en la página, la escena y la pantalla, Barcelona, Alba.

NARBOna, Antonio (1989), Sintaxis española: nuevos y viejos enfoques, Barcelona, Ariel.

NARbOna, Antonio (2001), «Diálogo literario y escritura(lidad)-oralidad», en R. Eberenz (ed.), Diálogo y oralidad en la narrativa hispánica moderna. Perspectivas literarias y lingüisticas, Madrid, Verbum, págs. 189-208.

PÉRez Bowie, José Antonio (2008), Leer el cine. La teoría literaria en la teoría cinematográfica, Universidad de Salamanca.

Pérez Martínez, Ana María (2004), «Dimensión textual del cine y el teatro: puntos de encuentro», en J. D. Vera Méndez y A. Sánchez Jordán (eds.), Cine y literatura: el teatro en el cine, Universidad de Murcia, págs. 23-30.

RodríGuEZ, Bonifacio (1997), «Argot y lenguaje coloquial», en A. Briz et al. (eds.), Pragmática y gramática del español hablado. Actas del II Simposio sobre análisis del discurso oral, Zaragoza, Libros Pórtico, págs. 225-239.

SANTAMARÍA PÉREZ, Isabel (2001), El argot y las jergas, Madrid, Liceus.

SECO, Manuel (1973), «La lengua coloquial: Entre visillos, de Carmen Martín Gaite», en AA. VV., El comentario de textos, Madrid, Castalia, págs. 361-379.

SeCo, Manuel (1983), Ortografía, reglas y comentarios, Universidad de Sofía.

TAmayo, Fermín y Eugenia Popeanga (2019), «Introducción» a J. L. Alonso de Santos, Bajarse al moro, Madrid, Cátedra.

Tracy-Ventura, Nicole (2017), «Combining corpora and experimental data to investigate language learning during residence abroad: A study of lexical sophistication», System, 71, págs. 35-45.

Trudgill, Peter (2000), Sociolinguistics. An introduction to language and society, London, Penguin.

VÉLIZ, Mónica (1999), «Complejidad sintáctica y modo del discurso», Estudios filológicos, 34, págs. 181-192.

Wardhaugh, Ronald y Janet M. Fuller (2014), An Introduction to Sociolinguistics, Hoboken, Wiley-Blackwell.

Wolf, Sergio (2001), Cine/literatura. Ritos de pasaje, Buenos Aires, Paidós.

Wilcoxon, Frank (1945), «Individual Comparisons by Ranking Methods», Biometrics, 1, págs. 80-83.

Fecha de recepción: 01/07/2019.

Fecha de aceptación: 25/07/2019. 